\title{
Locally Advanced Breast Cancer: Treatment Patterns and Predictors of Survival in a Saudi Tertiary Center
}

Nora H. Trabulsi ${ }^{1}$, Alaa A. Shabkah ${ }^{1}$, Reem Ujaimi ${ }^{2}$, Omar Iskanderani ${ }^{2}$, Mai S. Kadi ${ }^{3}$, Nuran Aljabri ${ }^{1}$, Liane Sharbatly ${ }^{1}$, Manal N. AlOtaibi ${ }^{1}$, Ali H. Farsi ${ }^{1}$, Mohammed O. Nassif ${ }^{1}$, Abdulaziz M. Saleem ${ }^{1}$, Nouf Y. Akeel ${ }^{1}$, Nadim H. Malibary ${ }^{1}$, Ali A. Samkari ${ }^{1}$

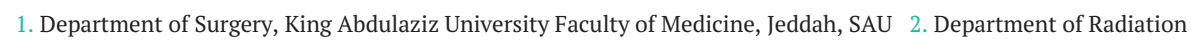
Oncology, King Abdulaziz University Faculty of Medicine, Jeddah, SAU 3. Department of Community Medicine, King Abdulaziz University, Jeddah, SAU

Corresponding author: Nora H. Trabulsi, noratrabulsi@gmail.com

\section{Abstract \\ Background}

Breast cancer (BC) is the most common cancer in the Kingdom of Saudi Arabia (KSA) and the second leading cause of cancer-related mortality. About $40 \%$ of BC in KSA is locally advanced BC (LABC), which has been associated with poorer survival compared with early diagnosed BC.

\section{Objective}

To review the presentation and outcomes of LABC, including the characteristics of the disease, different treatment modalities, overall survival (OS), disease-free survival (DFS), and local recurrence in relation to different radiotherapy (RT) techniques.

\section{Methods}

We retrospectively reviewed the medical records of 153 female patients with pathologically proven LABC diagnosed at King Abdulaziz University Hospital, Jeddah, KSA, between 2009 and 2017. We obtained data on patient demographics, stage of cancer at diagnosis, tumor characteristics (subtype and receptor status), type of surgery, systemic treatments received (hormonal, targeted therapy, and chemotherapy), RT variables, and recurrence and death dates. Data were analyzed to assess OS and DFS by using Kaplan-Meier analyses and the log-rank test. Univariate and multivariate Cox proportional hazard regression analyses were used to explore and identify factors associated with survival.

\section{Results}

Review began 05/01/2021 Review ended 05/31/2021 Published 06/08/2021

\section{(c) Copyright 2021}

Trabulsi et al. This is an open access article distributed under the terms of the Creative Commons Attribution License CC-BY 4.0., which permits unrestricted use, distribution, and reproduction in any medium, provided the original author and source are credited.
The median survival time in the study population was 9.16 years. Older age (65+ years) was associated with worse OS and DFS than was younger age ( $<65$ years) (hazard ratio (HR) 3.20, 95\% CI 1.48-6.90, P = 0.003 and HR $2.21,95 \%$ CI 1.12-4.36, P = 0.022, respectively). Regarding the type of surgery, having a mastectomy was associated with worse OS and DFS than was having a lumpectomy (HR 2.44, 95\% CI 0.97-6.12, P = 0.05 and HR 2.41, 95\% CI 1.13-5.14, $\mathrm{P}=0.023$, respectively). Positive estrogen and progesterone receptor status was associated with better OS and DFS than was a negative estrogen or progesterone receptor status (HR 0.13 , 95\% CI 0.05-0.30, P < 0.001 and HR 0.21, 95\% CI 0.11-0.41, P < 0.001, respectively). Patients who received RT had a lower risk of recurrence than did those who did not receive RT $(\mathrm{P}=0.011)$. Moreover, threedimensional conformal RT was associated with lower local recurrence than intensity-modulated RT or volumetric-modulated arc therapy $(\mathrm{P}=0.003)$.

\section{Conclusion}

Multiple factors can affect the OS and DFS in LABC. Younger patients, having hormone-positive disease, and undergoing lumpectomy were associated with better outcomes. Adjuvant RT may improve local control and the use of three-dimensional conformal RT was superior for local control. Prospective studies with larger sample sizes are needed to further highlight these findings and to assess the role of chemotherapy and targeted therapy in patients with LABC.

Categories: Radiation Oncology, General Surgery, Oncology

Keywords: locally advanced, breast cancer, survival, overall survival, relapse, disease-free survival, outcome, saudi arabia

\section{Introduction}

In 2020, there were $2,261,419$ new cases of breast cancer (BC) worldwide, accounting for $11.7 \%$ of all types of 
cancer. BC is the fifth leading cause of cancer-related mortality, comprising $6.9 \%$ of cancer-related deaths [1].

In the Kingdom of Saudi Arabia (KSA), BC is the most common cancer, accounting for $16.7 \%$ of all cancer cases and 30\% of all cancer cases among Saudi women. Moreover, it is the second leading cause of cancerrelated mortality in KSA, accounting for $8.4 \%$ of cancer-related deaths [1]. About $40 \%$ of BC is locally advanced $\mathrm{BC}(\mathrm{LABC})$ at the time of diagnosis [2].

LABC is an unusual presentation among women in the United States and Europe, as it accounts for only $4 \%$ $8 \%$ of cases of BC, whereas LABC is more common in KSA [2,3]. This could be attributed to multiple factors, including the absence of a national screening program in KSA and difficult access to healthcare facilities [4]. Even though LABC is not common in Western countries, most of the available studies in the literature that have explored different aspects of LABC have been conducted in Western countries, with a scarce number being performed in countries in the Middle East, including KSA.

Given its advanced presentation, LABC is associated with poor survival. The median survival of LABC across previous studies ranged between 28 and 66 months, and the five-year overall survival (OS) is reported to be between $40 \%$ and $75 \%$ [5-8]. Disease-free survival (DFS) is reported to be around $67 \%$ in three years [9] and the five-year locoregional recurrence rate (LRR) is $7 \%-9 \%[10,11]$.

Neoadjuvant and adjuvant therapies are required in addition to surgery to reduce the LRR [12]. Adjuvant radiotherapy (RT) has been shown to improve locoregional control in LABC [13], but the influence of different RT techniques on the LRR has not been well studied.

The aim of our research was therefore to review the presentation and outcomes of LABC at a major hospital in KSA in relation to different RT techniques, including the characteristics of the disease, different treatment modalities, OS, DFS, and local recurrence.

\section{Materials And Methods \\ Study design and population}

In this study, we examined a cohort of 153 patients who were diagnosed with LABC in King Abdulaziz University Hospital (KAUH) between 2009 and 2017 and were followed up to January 2020 to assess outcome. KAUH is a major university hospital and a tertiary care center in Jeddah, Saudi Arabia, that serves as one of the cancer referral centers. Approval for this study was granted by the Research Committee of the Unit of Biomedical Ethics at KAUH (Reference number 464-17).

\section{Data collection and endpoints}

We performed a retrospective review of the medical records of female patients with pathologically proven LABC diagnosed at KAUH between 2009 and 2017. LABC was defined on the basis of the tumor-nodemetastasis (TNM) pathological staging system, according to the American Joint Committee on Cancer [14], as any patient who presented with stage III disease (T3N1, T4, inflammatory BC, or N2-N3 disease). Patients with early BC (stage I-II) or metastatic disease (stage IV) were excluded.

For each patient, we obtained demographics, stage of cancer at the time of diagnosis (TNM), tumor characteristics (subtype and receptor status), type of surgery, systemic treatments received (hormonal, targeted therapy, and chemotherapy), RT variables, and recurrence and death dates. The primary endpoints were the OS and DFS rates and the factors associated with them. The secondary endpoint was local recurrence in relation to different $\mathrm{RT}$ techniques.

\section{Data analysis}

Statistical analysis was performed with R v 3.6.2 (R Studio, version 3.5.2, Boston, MA, USA). Data were summarized as mean \pm standard deviation for continuous variables and as counts (percentages) for categorical variables. Survival analysis was used to model the time to event (death) since the diagnosis of LABC. Survival time was calculated for each patient. Surviving patients were censored at the date of the last follow-up.

The Kaplan-Meier estimator was used to compare survival across groups and the log-rank test to compare survival between groups. The maximally selected rank statistics were used to identify a cut-off point for age. Univariate Cox proportional hazard $(\mathrm{CPH})$ regression analysis was used to explore factors associated with survival. Significant predictors (identified in univariate $\mathrm{CPH}$ ) were used in a multivariate $\mathrm{CPH}$ model to derive a model that can predict survival. The predictive power of the model was assessed by using indexcorrected Somers' D (Dxy). The adjusted hazard ratio (HR) and associated 95\% confidence interval (CI) were calculated for each of the predictors in the final model. Hypothesis testing was performed at a $5 \%$ level of significance. 


\section{Cureus}

A nomogram was developed on the basis of the final multivariate $\mathrm{CPH}$ model. Points corresponding to the value of each predictor were calculated by using the nomogram and added to develop a total score; the predicted five-year survival probability ( $\geqslant 5$ years) was calculated based on the overall score. Model validation was performed by using 1000 bootstrapped samples. The predictive power of the model was assessed with index-corrected Somers' D (Dxy).

\section{Results}

\section{Descriptive statistics}

Patient demographics are shown in Table 1. A total of 153 patients who were diagnosed with LABC in our institute were enrolled in this study. Their mean age was 54.3 years (SD 12.3). Regarding pathological classification, $80 \%$ of LABC was invasive ductal BC and13\% invasive lobular BC. Around $42 \%$ of patients had $\mathrm{T} 3 / 4$ tumors and $43 \%$ had a lymph node status of N2/3. The majority of patients (59.5\%) were diagnosed with estrogen (ER)+/progesterone (PR)+ (PP) tumors, $77.8 \%$ of the patients did not express the human epidermal growth factor receptor type 2 (HER2) gene (HER2-), and 17.95\% had triple-negative tumors (ER-/PR- (NN), HER2-). 


\section{Cureus}

\begin{tabular}{|c|c|}
\hline Characteristic & $N=153$ \\
\hline Age (SD) & $54.3(12.3)$ \\
\hline \multicolumn{2}{|l|}{ Diagnosis } \\
\hline Ductal & $122(79.7 \%)$ \\
\hline Lobular & $20(13.1 \%)$ \\
\hline Other & $11(7.19 \%)$ \\
\hline \multicolumn{2}{|l|}{ T stage } \\
\hline $\mathrm{T} 1 / 2$ & 88 (57.5\%) \\
\hline T3/4 & 65 (42.5\%) \\
\hline \multicolumn{2}{|l|}{ N stage } \\
\hline N0/1 & $87(56.9 \%)$ \\
\hline $\mathrm{N} 2 / 3$ & 66 (43.1\%) \\
\hline \multicolumn{2}{|l|}{ ER/PR status ${ }^{\star}$} \\
\hline NN & $42(27.5 \%)$ \\
\hline NP & 20 (13.1\%) \\
\hline PP & $91(59.5 \%)$ \\
\hline \multicolumn{2}{|l|}{ HER2 status } \\
\hline Negative & 119 (77.8\%) \\
\hline Positive & $34(22.2 \%)$ \\
\hline \multicolumn{2}{|c|}{ Targeted therapy } \\
\hline No & $124(81.0 \%)$ \\
\hline Yes & 29 (19.0\%) \\
\hline \multicolumn{2}{|l|}{ Radiotherapy } \\
\hline No & $32(20.9 \%)$ \\
\hline Yes & $121(79.1 \%)$ \\
\hline \multicolumn{2}{|l|}{ Chemotherapy } \\
\hline None & $21(13.7 \%)$ \\
\hline Adjuvant & $81(52.9 \%)$ \\
\hline Neoadjuvant & 51 (33.3\%) \\
\hline \multicolumn{2}{|c|}{ Type of breast surgery } \\
\hline Lumpectomy & $45(29.4 \%)$ \\
\hline Mastectomy & 108 (70.6\%) \\
\hline
\end{tabular}

TABLE 1: Descriptive statistics of patients with locally advanced breast cancer included in the study.

ER: estrogen receptor; PR, progesterone receptor.

*ER and PR status were combined as both negative (NN), both positive (PP), or only one positive (NP). 


\section{Cureus}

The majority (81\%) did not receive targeted therapy, but most (79.1\%) received adjuvant RT. Mastectomy was performed in $70.6 \%$ of the patients. The median survival time in the study population was 9.16 years.

\section{Overall survival}

Univariate Analysis

Our data showed that age, receptor status, and type of surgery were important predictors of OS, each identified by using univariate $\mathrm{CPH}$ regression to estimate the risk of death in patients with LABC. Patients who were 65 years or older at the time of diagnosis were almost twice as likely to die as patients who were $<65$ years (HR 2.08, 95\% CI 1.00-4.31, P = 0.049) (Table 2). Survival curves across different age groups are shown in Figure 1.

\begin{tabular}{|c|c|c|c|c|c|c|}
\hline \multirow{3}{*}{ Characteristic } & \multicolumn{4}{|c|}{ Univariate analysis } & \multicolumn{2}{|c|}{ Multivariate analysis } \\
\hline & Alive & Dead & HR & P-value & HR & P-value \\
\hline & $N=120$ & $N=33$ & & & & \\
\hline \multicolumn{7}{|l|}{ Age } \\
\hline$<65$ & $103(82.4 \%)$ & $22(17.6 \%)$ & Ref & Ref & Ref & Ref \\
\hline $65+$ & 17 (60.7\%) & $11(39.3 \%)$ & $2.08(1.00-4.31)$ & 0.049 & $3.20(1.48-6.90)$ & 0.003 \\
\hline \multicolumn{7}{|l|}{ Diagnosis } \\
\hline Ductal & 96 (78.7\%) & $26(21.3 \%)$ & Ref & Ref & & \\
\hline Lobular & 18 (90.0\%) & $2(10.0 \%)$ & $0.29(0.07-1.24)$ & 0.095 & & \\
\hline Other & 6 (54.5\%) & 5 (45.5\%) & $2.61(1.00-6.85)$ & 0.051 & & \\
\hline \multicolumn{7}{|l|}{ T stage } \\
\hline T1/2 & 74 (84.1\%) & 14 (15.9\%) & Ref & Ref & & \\
\hline T3/4 & 46 (70.8\%) & $19(29.2 \%)$ & 2.22 (1.11-4.44) & 0.025 & & \\
\hline \multicolumn{7}{|l|}{$\mathrm{N}$ stage } \\
\hline N0/1 & 75 (86.2\%) & $12(13.8 \%)$ & Ref & Ref & & \\
\hline $\mathrm{N} 2 / 3$ & $45(68.2 \%)$ & $21(31.8 \%)$ & $2.08(1.02-4.23)$ & 0.044 & & \\
\hline \multicolumn{7}{|l|}{ ER/PR status* } \\
\hline NN & 24 (57.1\%) & 18 (42.9\%) & Ref & Ref & Ref & Ref \\
\hline NP & 14 (70.0\%) & 6 (30.0\%) & $0.59(0.23-1.50)$ & 0.270 & 0.48 (0.19-1.22) & 0.122 \\
\hline PP & 82 (90.1\%) & 9 (9.89\%) & $0.17(0.08-0.39)$ & $<0.001$ & $0.13(0.05-0.30)$ & $<0.001$ \\
\hline \multicolumn{7}{|l|}{ HER2 status } \\
\hline Negative & 92 (77.3\%) & 27 (22.7\%) & Ref & Ref & & \\
\hline Positive & 28 (82.4\%) & $6(17.6 \%)$ & 1.15 (0.47-2.83) & 0.765 & & \\
\hline \multicolumn{7}{|c|}{ Targeted therapy } \\
\hline No & 96 (77.4\%) & $28(22.6 \%)$ & Ref & Ref & & \\
\hline Yes & 24 (82.8\%) & $5(17.2 \%)$ & $1.14(0.43-3.04)$ & 0.788 & & \\
\hline \multicolumn{7}{|l|}{ Radiotherapy } \\
\hline No & 22 (68.8\%) & $10(31.2 \%)$ & Ref & Ref & & \\
\hline Yes & 98 (81.0\%) & $23(19.0 \%)$ & $0.69(0.33-1.47)$ & 0.343 & & \\
\hline \multicolumn{7}{|l|}{ Chemotherapy } \\
\hline None & 16 (76.2\%) & $5(23.8 \%)$ & Ref & Ref & & \\
\hline Adjuvant & $66(81.5 \%)$ & 15 (18.5\%) & $0.65(0.24-1.80)$ & 0.407 & & \\
\hline
\end{tabular}




\section{Cureus}

$\begin{array}{lllll}\text { Neoadjuvant } & 38(74.5 \%) & 13(25.5 \%) & 1.61(0.57-4.57) & 0.373\end{array}$

Type of breast surgery

$\begin{array}{lllllll}\text { Lumpectomy } & 39(86.7 \%) & 6(13.3 \%) & \text { Ref } & \text { Ref } & \text { Ref } & \text { Ref } \\ \text { Mastectomy } & 81(75.0 \%) & 27(25.0 \%) & 2.76(1.13-6.72) & 0.026 & 2.44(0.97-6.12) & 0.05\end{array}$

TABLE 2: Univariate and multivariate Cox proportional hazard regression analysis to estimate the risk of death in patients diagnosed with locally advanced breast cancer.

ER: estrogen receptor; HR: hazard ratio; PR: progesterone receptor; Ref: reference category.

*Estrogen receptor (ER) and progesterone receptor (PR) status were combined as both negative (NN), both positive (PP), or only one positive (NP).

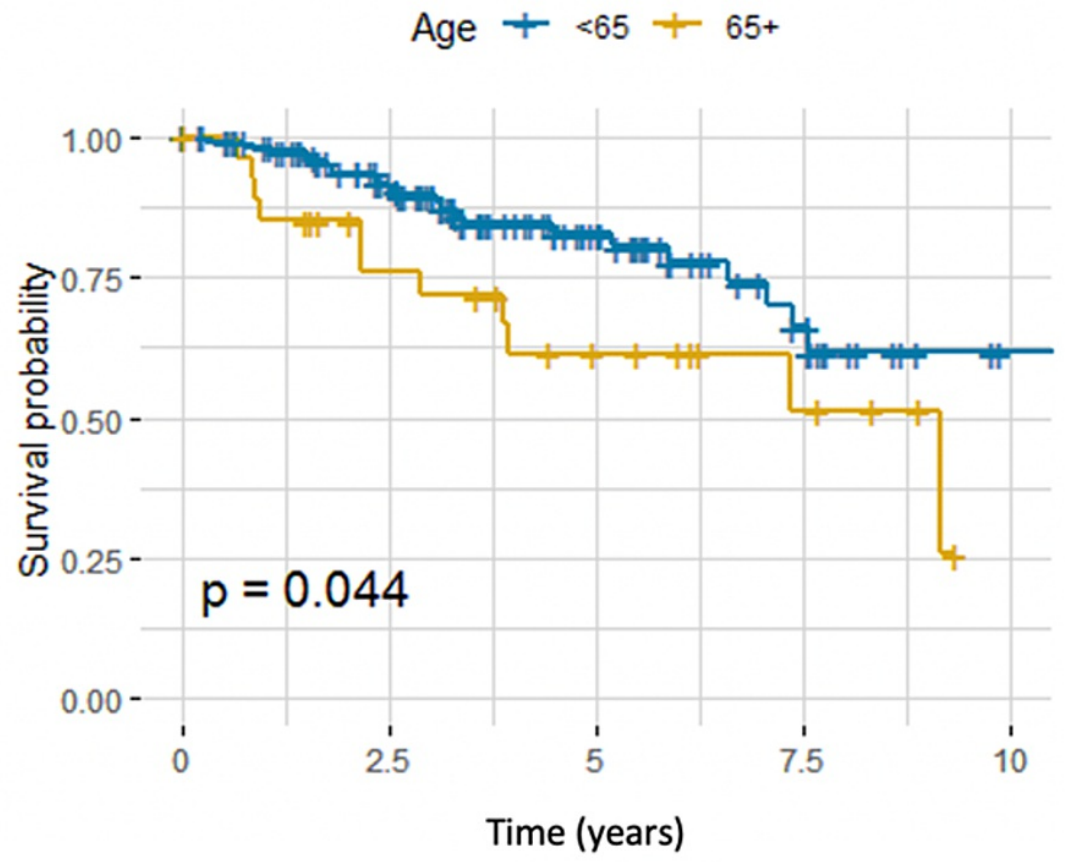

FIGURE 1: Kaplan-Meier estimator for age groups, log-rank test $(P=$ 0.044).

Having a tumor that expressed receptors for both ER and PR (PP) was associated with better OS than was having a tumor that expressed receptors for neither (NN) (HR 0.17, 95\% CI 0.08-0.39, P < 0.001), whereas having a tumor that expressed receptors for only one (NP) did not influence survival status (Table 2). Survival curves across different groups are shown in Figure 2. 


\section{Cureus}

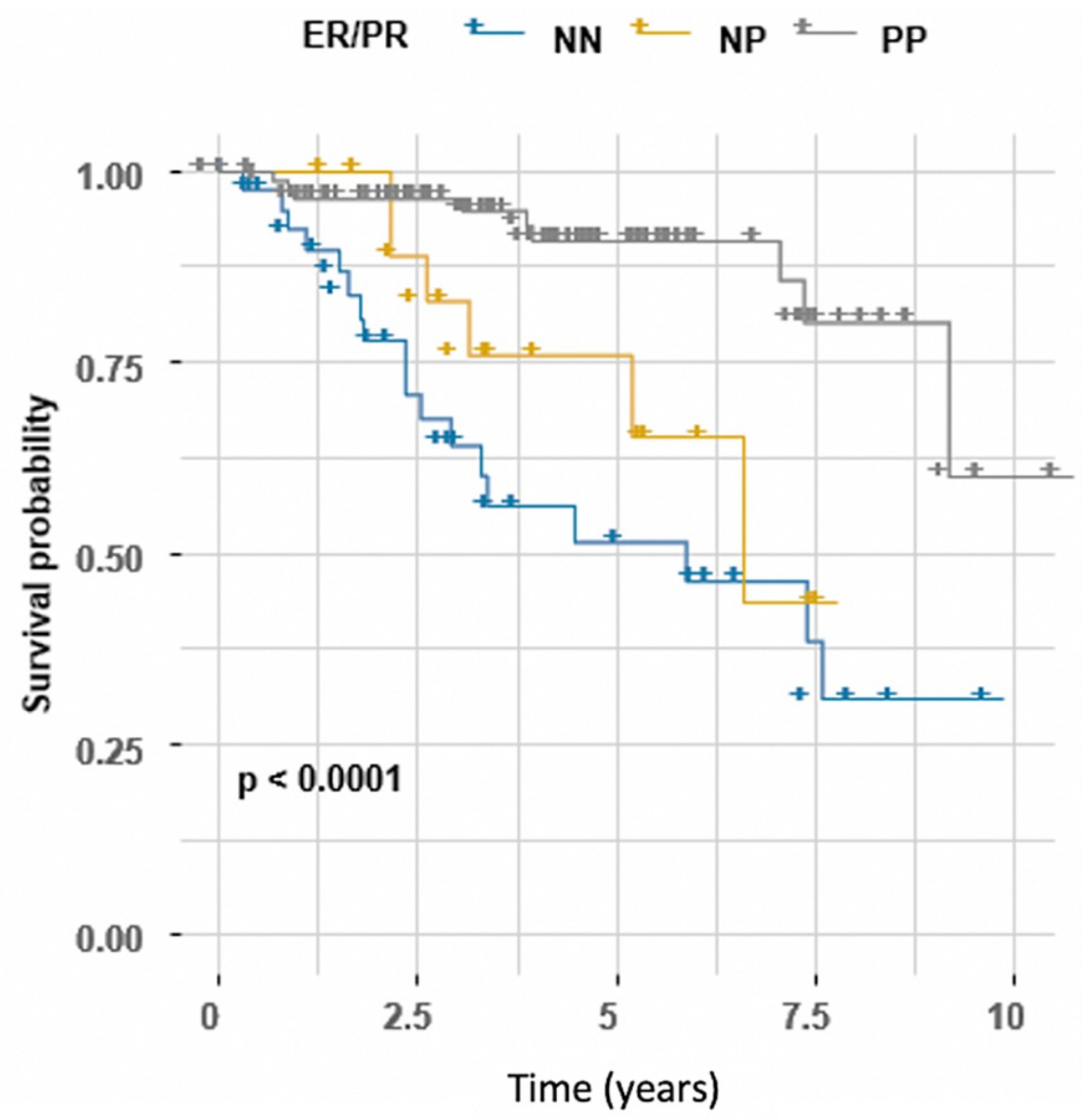

FIGURE 2: Kaplan-Meier estimator for estrogen (ER)/progesterone (PR) status, log-rank test $(P<0.0001)$.

ER and PR status were combined as both negative (NN), both positive (PP), or only one positive (NP).

Higher $\mathrm{T}$ and $\mathrm{N}$ stages were associated with a higher hazard of death (HR 2.22, 95\% CI 1.11-4.44, $\mathrm{P}=0.025$ and HR 2.08, 95\% CI 1.02-4.23, $\mathrm{P}=0.044$, respectively) (Table 2).

Moreover, the hazard of death in patients who underwent mastectomy was significantly higher than in patients who underwent lumpectomy (HR 2.76, 95\% CI 1.13-6.72, P =0.026) (Table 2). Survival curves across both groups are shown in Figure 3. 


\section{Cureus}

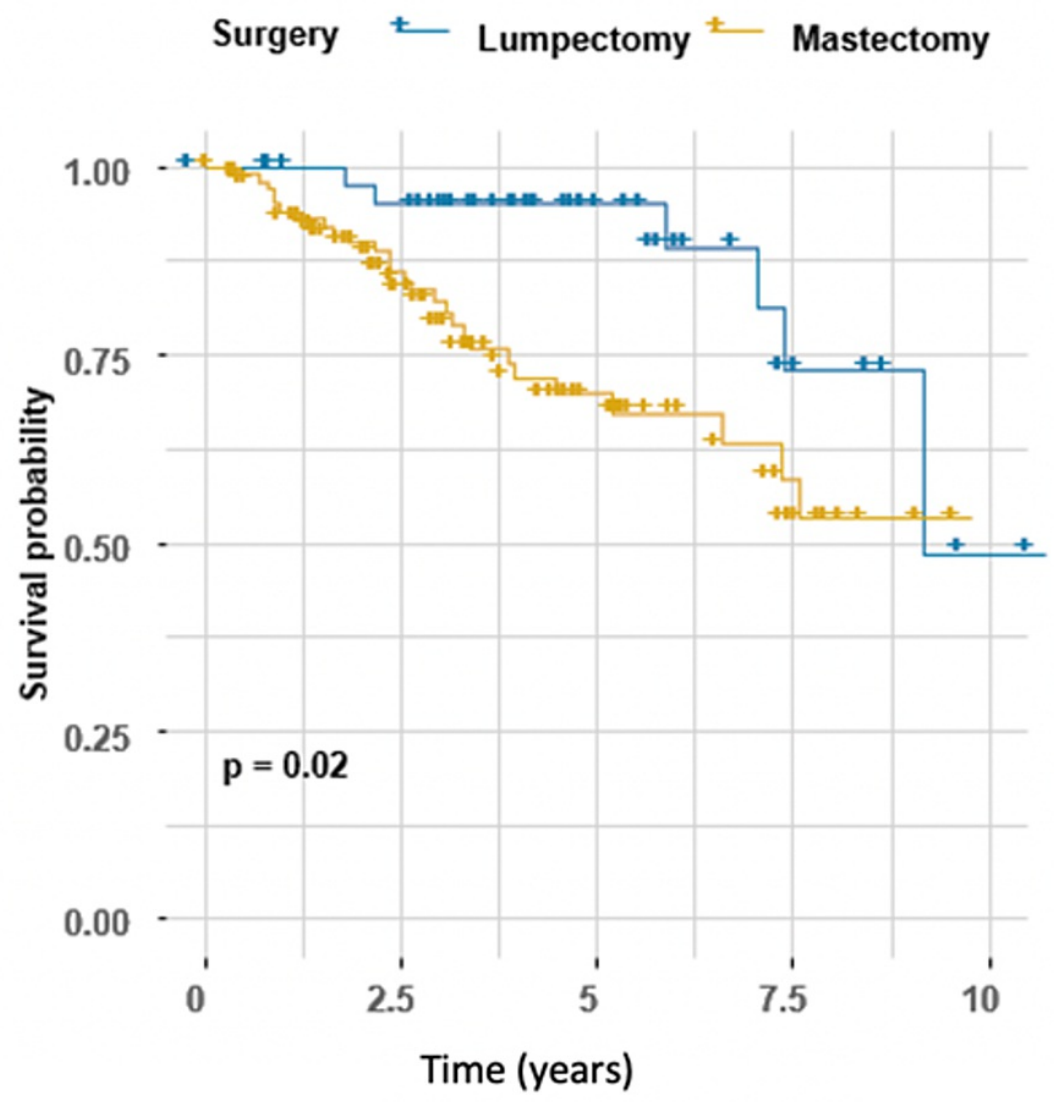

FIGURE 3: Kaplan-Meier estimator for surgery, log-rank test $(P=0.02)$.

HER2 status and treatment with chemotherapy, targeted therapy, or RT were not significantly associated with OS.

\section{Multivariate Analysis}

Multivariate $\mathrm{CPH}$ regression analysis was performed to estimate the risk of death in patients diagnosed with LABC. The final multivariate model is shown in Table 2. Age, receptor status, and type of breast surgery were predictors of death.

The five-year survival prediction nomogram of the study population was validated by using 1,000 bootstrapped samples. The corrected Somers' index (Dxy) was $58.41 \%$, indicating a $58.41 \%$ conformity between the predicted and observed survival times. A patient who was $<65$ years at diagnosis and who had a lumpectomy of a tumor that expressed ER/PR (PP) had a greater than 90\% probability of five-year survival (Figure 4). 


\section{Cureus}

Points

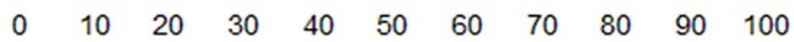

Age

$65+$

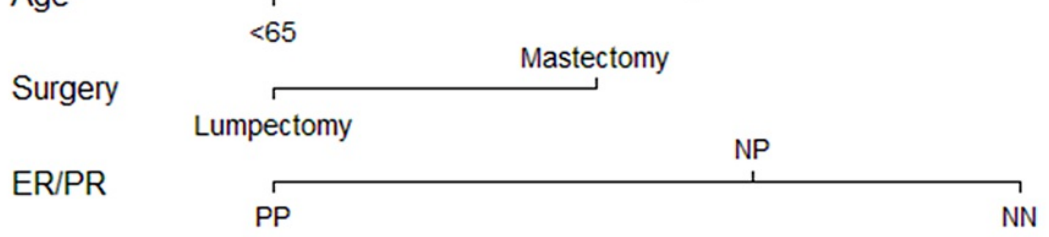

Total Points

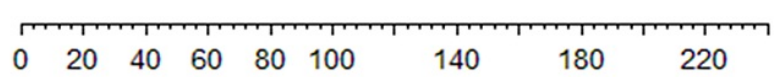

5-year survival

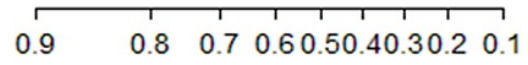

FIGURE 4: Validated nomogram to predict five-year survival of patients with locally advanced breast cancer.

Estrogen receptor (ER) and progesterone receptor (PR) status were combined as both negative (NN), both positive (PP), or only one positive (NP).

\section{Disease-free survival}

Univariate Analysis

Our data showed that the type of BC, N stage, ER/PR status, and type of breast surgery were significant predictors for DFS, all of which were identified by using univariate $\mathrm{CPH}$ regression (Table 3). Lobular carcinoma was associated with a lower risk of recurrence than was ductal carcinoma (HR 0.19, 95\% CI 0.05$0.81, \mathrm{P}=0.024$ ) (Table 3). Survival curves across different pathological types of BC are shown in Figure 5.

\begin{tabular}{|c|c|c|c|c|c|c|}
\hline \multirow{3}{*}{ Characteristic } & \multicolumn{4}{|c|}{ Univariate analysis } & \multicolumn{2}{|c|}{ Multivariate analysis } \\
\hline & No event & Event & HR & P-value & HR & P-value \\
\hline & $N=108$ & $N=45$ & & & & \\
\hline \multicolumn{7}{|l|}{ Age } \\
\hline$<65$ & $93(74.4 \%)$ & $32(25.6 \%)$ & Ref & Ref & Ref & Ref \\
\hline $65+$ & $15(53.6 \%)$ & $13(46.4 \%)$ & 1.64 (0.85-3.15) & 0.140 & $2.21(1.12-4.36)$ & 0.022 \\
\hline \multicolumn{7}{|l|}{ Diagnosis } \\
\hline Ductal & $83(68.0 \%)$ & $39(32.0 \%)$ & Ref & Ref & & \\
\hline Lobular & $18(90.0 \%)$ & $2(10.0 \%)$ & $0.19(0.05-0.81)$ & 0.024 & & \\
\hline Other & $7(63.6 \%)$ & $4(36.4 \%)$ & 1.49 (0.53-4.21) & 0.448 & & \\
\hline \multicolumn{7}{|l|}{ T stage } \\
\hline $\mathrm{T} 1 / 2$ & $66(75.0 \%)$ & $22(25.0 \%)$ & Ref & Ref & & \\
\hline T3/4 & $42(64.6 \%)$ & $23(35.4 \%)$ & $1.76(0.97-3.16)$ & 0.061 & & \\
\hline \multicolumn{7}{|l|}{$\mathrm{N}$ stage } \\
\hline N0/1 & $70(80.5 \%)$ & 17 (19.5\%) & Ref & Ref & & \\
\hline $\mathrm{N} 2 / 3$ & $38(57.6 \%)$ & 28 (42.4\%) & $1.96(1.07-3.59)$ & 0.029 & & \\
\hline \multicolumn{7}{|l|}{ ER/PR status* } \\
\hline NN & $21(50.0 \%)$ & $21(50.0 \%)$ & Ref & Ref & Ref & Ref \\
\hline
\end{tabular}




\section{Cureus}

\begin{tabular}{|c|c|c|c|c|c|c|}
\hline NP & $12(60.0 \%)$ & 8 (40.0\%) & $0.67(0.30-1.52)$ & 0.341 & $0.55(0.24-1.26)$ & 0.157 \\
\hline PP & 75 (82.4\%) & 16 (17.6\%) & $0.26(0.13-0.50)$ & $<0.001$ & $0.21(0.11-0.41)$ & $<0.001$ \\
\hline \multicolumn{7}{|l|}{ HER2 status } \\
\hline Negative & 84 (70.6\%) & 35 (29.4\%) & Ref & Ref & & \\
\hline Positive & 24 (70.6\%) & 10 (29.4\%) & $1.49(0.72-3.06)$ & 0.280 & & \\
\hline \multicolumn{7}{|c|}{ Targeted therapy } \\
\hline No & 87 (70.2\%) & 37 (29.8\%) & Ref & Ref & & \\
\hline Yes & 21 (72.4\%) & $8(27.6 \%)$ & $1.36(0.62-2.99)$ & 0.441 & & \\
\hline \multicolumn{7}{|l|}{ Radiotherapy } \\
\hline No & 19 (59.4\%) & 13 (40.6\%) & Ref & Ref & & \\
\hline Yes & 89 (73.6\%) & 32 (26.4\%) & $0.72(0.38-1.39)$ & 0.331 & & \\
\hline \multicolumn{7}{|l|}{ Chemotherapy } \\
\hline None & 14 (66.7\%) & 7 (33.3\%) & Ref & Ref & & \\
\hline Adjuvant & 66 (81.5\%) & 15 (18.5\%) & 0.45 (0.18-1.12) & 0.086 & & \\
\hline Neoadjuvant & 28 (54.9\%) & 23 (45.1\%) & $1.98(0.84-4.67)$ & 0.119 & & \\
\hline \multicolumn{7}{|c|}{ Type of breast surgery } \\
\hline Lumpectomy & 36 (80.0\%) & 9 (20.0\%) & Ref & Ref & Ref & Ref \\
\hline Mastectomy & $72(66.7 \%)$ & 36 (33.3\%) & $2.54(1.21-5.32)$ & 0.013 & 2.41 (1.13-5.14) & 0.023 \\
\hline
\end{tabular}

TABLE 3: Univariate and multivariate Cox proportional hazard regression analysis to estimate the risk of disease-free survival in patients diagnosed with locally advanced breast cancer.

ER: estrogen receptor; HR: hazard ratio; PR: progesterone receptor; Ref: reference category.

*ER and PR status were combined as both negative (NN), both positive (PP), or only one positive (NP). 


\section{Cureus}

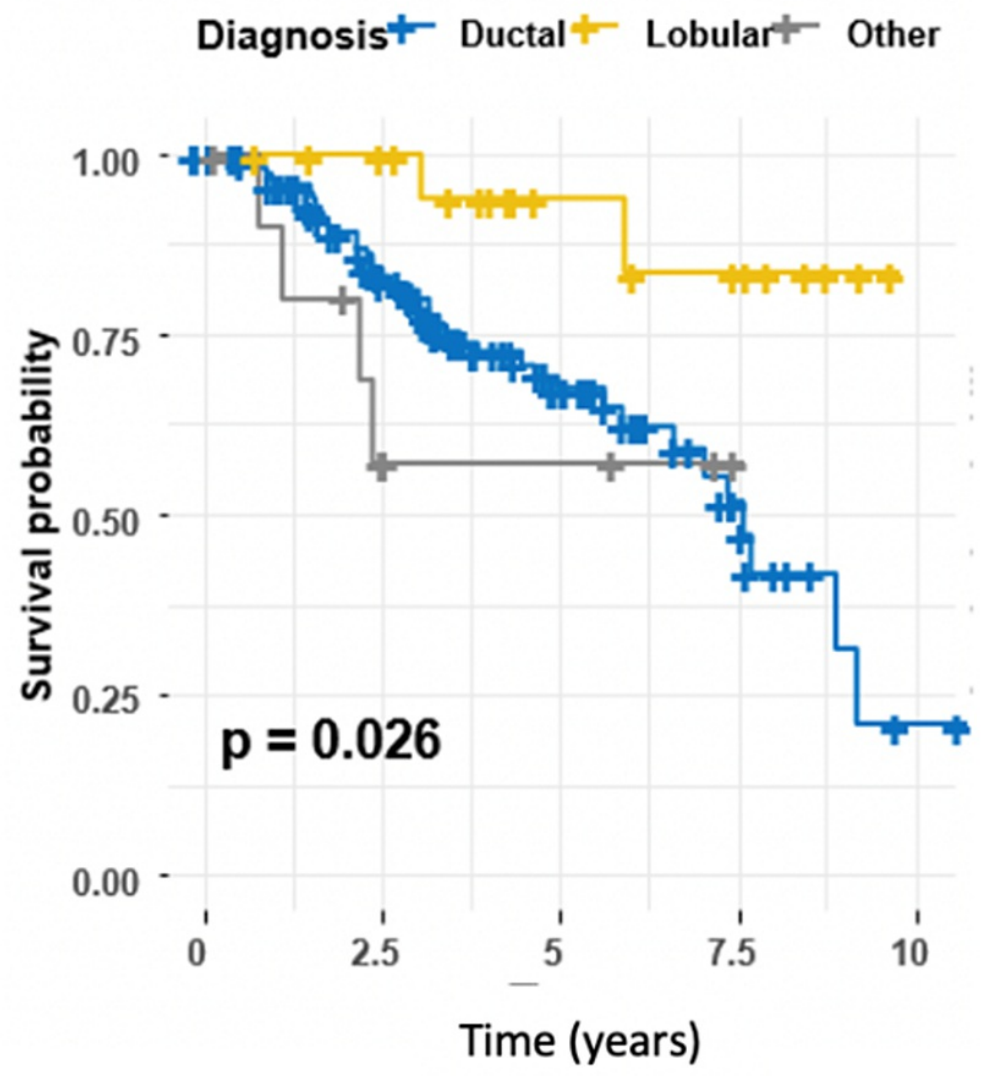

FIGURE 5: Kaplan-Meier estimator for the type of breast cancer, logrank test $(P=0.026)$.

Moreover, the results indicated that the risk of recurrence was twice as high in patients with $\mathrm{N}$ stage $2 / 3$ as in those with $\mathrm{N}$ stage $0 / 1$ (HR 1.96, 95\% CI 1.07-3.59, P = 0.029) (Table 3). Survival curves across both groups are shown in Figure 6. 


\section{Cureus}

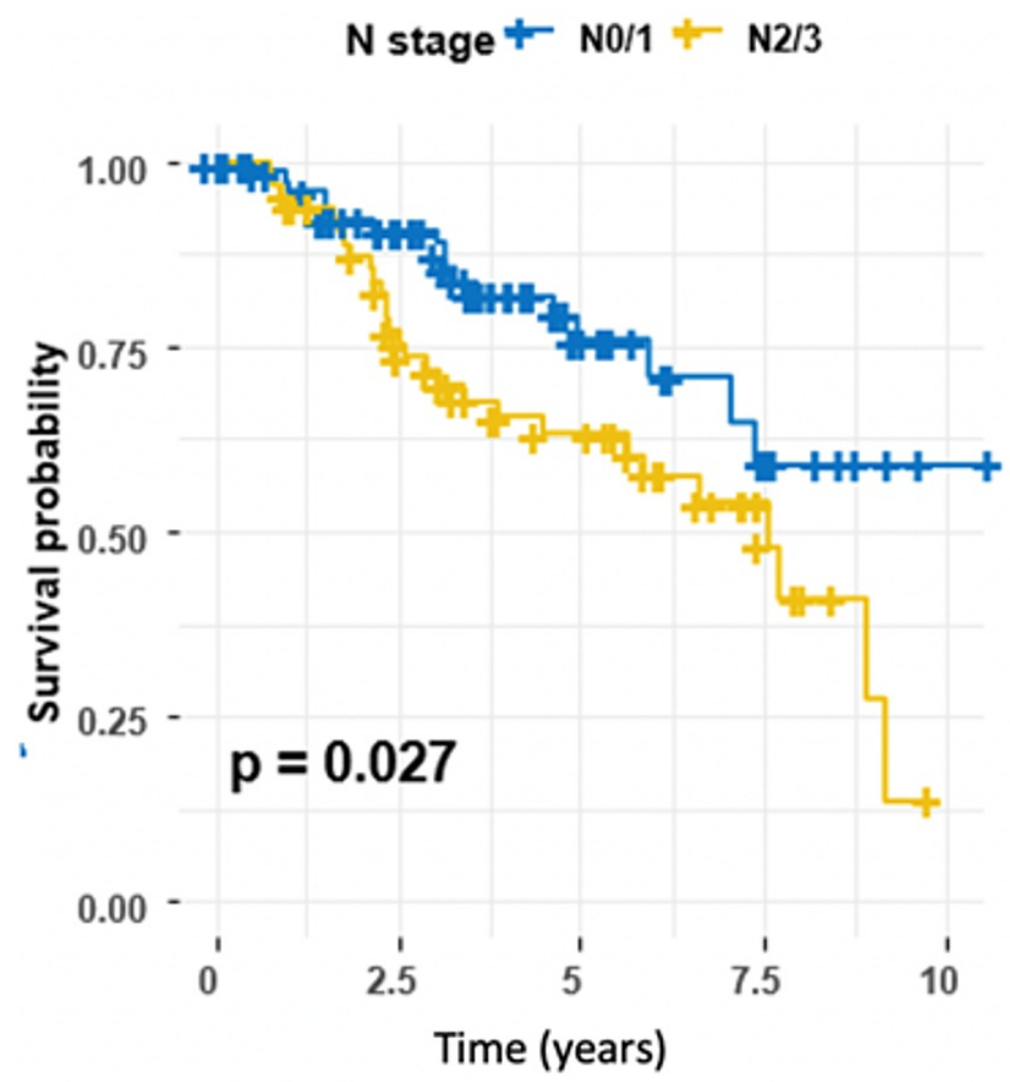

FIGURE 6: Kaplan-Meier estimator for $\mathrm{N}$ stage, log-rank test $(\mathrm{P}=0.027)$.

Regarding receptor status, tumors that expressed both ER and PR (PP) were associated with a lower risk of recurrence than were those that expressed neither (NN) (HR 0.26, 95\% CI 0.13-0.50, P < 0.001). However, expressing either ER or PR (NP) did not influence DFS (Table 3). Survival curves across different groups are shown in Figure 7. 


\section{Cureus}

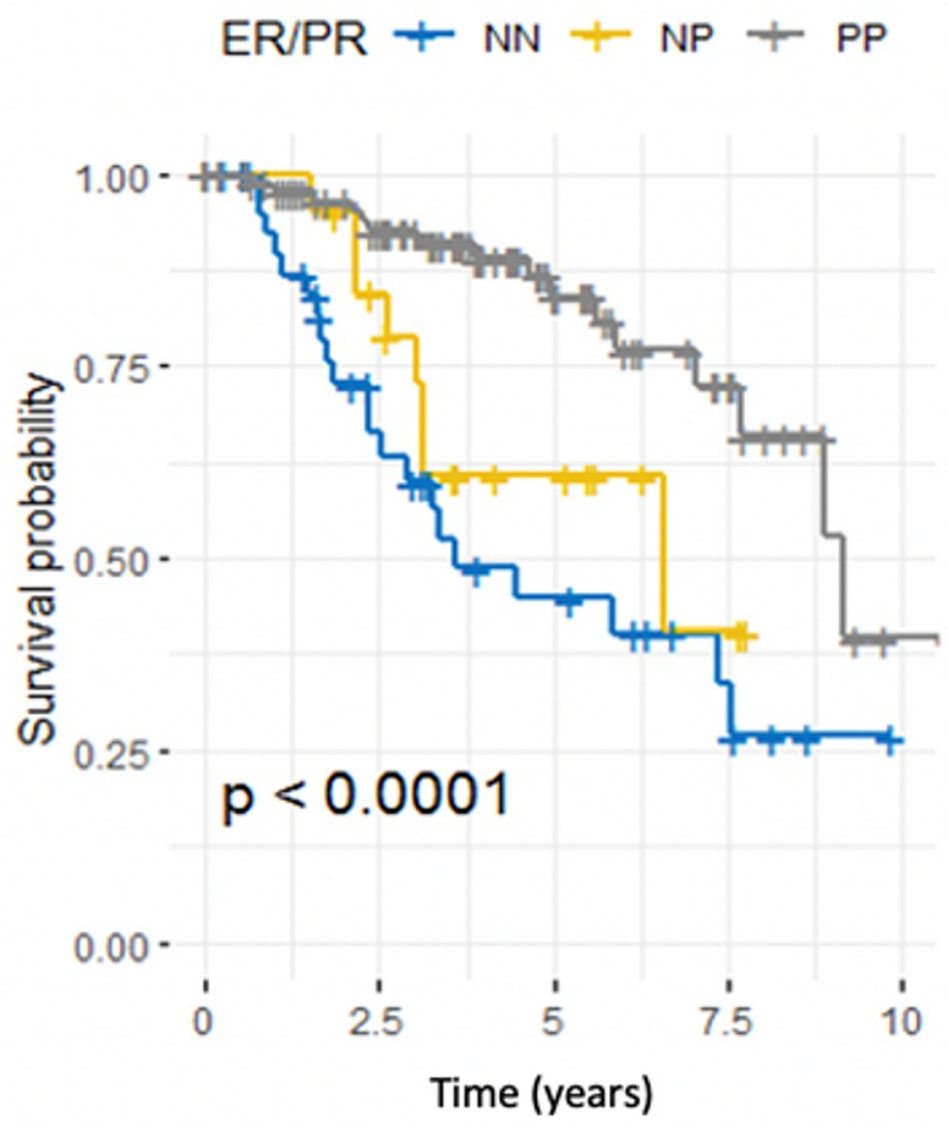

FIGURE 7: Kaplan-Meier estimator for estrogen receptor $(E R) /$ progesterone receptor $(P R)$ status, log-rank test $(P<0.001)$.

ER and PR status were combined as both negative (NN), both positive (PP), or only one positive (NP).

The risk of recurrence in patients who underwent mastectomy was significantly higher than in patients who underwent lumpectomy (HR 2.54, 95\% CI 1.21-5.32, P = 0.013) (Table 3). Survival curves across both groups are shown in Figure 8. 


\section{Cureus}

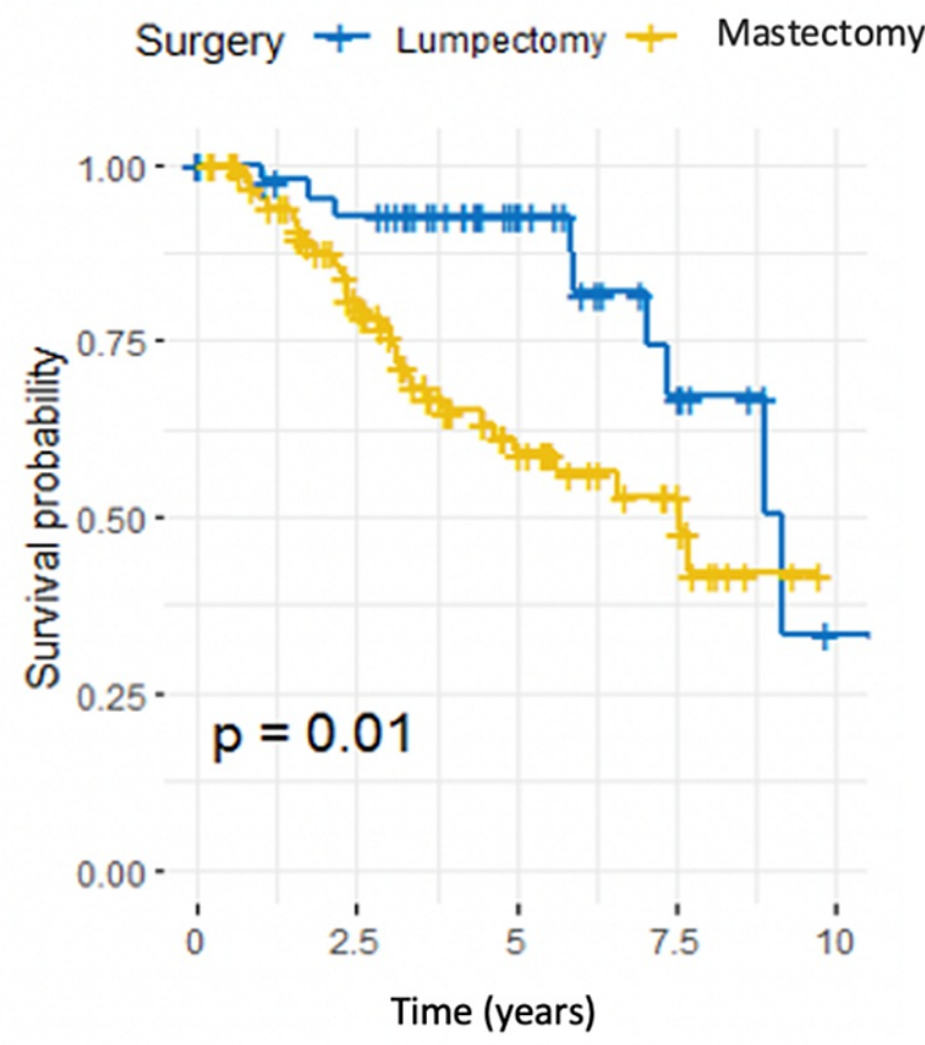

FIGURE 8: Kaplan-Meier estimator for the type of breast surgery, logrank test $(P=0.01)$.

HER2 status and treatment with chemotherapy, targeted therapy, or RT were not significantly associated with DFS.

\section{Multivariate Analysis}

Multivariate $\mathrm{CPH}$ regression analysis was performed to assess factors associated with disease relapse (Table 3). Age, receptor status, and type of breast surgery were predictors of disease relapse.

The five-year DFS prediction nomogram of the study population was validated by using 1,000 bootstrapped samples. The corrected Somers' index (Dxy) was 50.42\%, which indicates a 50.42\% concordance between the predicted and observed DFS times. A patient who was $<65$ years at diagnosis and who had a lumpectomy of a tumor that expressed ER and PR (PP) had a greater than $90 \%$ probability of five-year DFS (Figure 9). 


\section{Cureus}

Points

$\begin{array}{lllllllllll}0 & 10 & 20 & 30 & 40 & 50 & 60 & 70 & 80 & 90 & 100\end{array}$

$65+$

Age

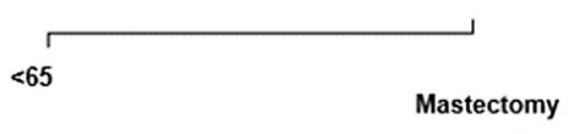

Surgery

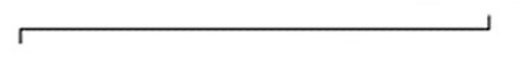

Lumpectomy

NP

ER/PR

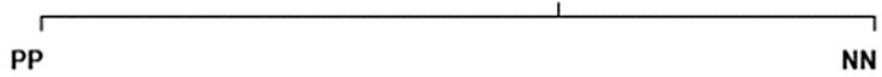

Total Points

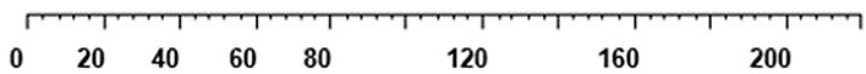

5 Year Disease

Free Survival

\begin{tabular}{llllllllll}
\hline 0.9 & 0.8 & 0.7 & 0.6 & 0.5 & 0.4 & 0.3 & 0.2
\end{tabular}

FIGURE 9: Validated nomogram to predict the probability of five-year disease-free survival for patients with locally advanced breast cancer.

Estrogen receptor (ER) and progesterone receptor (PR) status were combined as both negative (NN), both positive (PP), or only one positive (NP).

\section{Local recurrence and $\mathrm{RT}$}

Using the chi-square test of independence, we found that the risk of local recurrence was lower in patients with LABC who received RT than in those who did not $(\mathrm{P}=0.011)$. The risk of recurrence was also associated with the technique used for RT ( $\mathrm{P}=0.003)$ (Table 4$)$, as local recurrence occurred in $16.7 \%$ of patients who received step-and-shoot intensity-modulated RT (IMRT) and/or volumetric-modulated arc therapy (VMAT) but in 3.88\% of patients who received three-dimensional conformal RT (3D-CRT). There was no statistically significant difference in the proportion of patients with local recurrence according to field number, dose, and whether or not they received a skin dose. 


\section{Cureus}

\begin{tabular}{|c|c|c|c|}
\hline & \multicolumn{3}{|c|}{ Local recurrence } \\
\hline & No & Yes & P-value \\
\hline & $N=139$ & $N=14$ & \\
\hline Radiotherapy & & & 0.011 \\
\hline No & $25(78.1 \%)$ & $7(21.9 \%)$ & \\
\hline Yes & 114 (94.2\%) & $7(5.79 \%)$ & \\
\hline Technique & & & 0.003 \\
\hline 3D-CRT & $99(96.1 \%)$ & $4(3.88 \%)$ & \\
\hline SSIMRT + VMAT & $15(83.3 \%)$ & $3(16.7 \%)$ & \\
\hline Number of fields & & & 0.592 \\
\hline 0 & $18(100 \%)$ & $0(0.0 \%)$ & \\
\hline 1,2, and 3 & $96(93.2 \%)$ & $7(6.80 \%)$ & \\
\hline Skin dose & & & 0.302 \\
\hline 0 (bolus) & $97(95.1 \%)$ & $5(4.90 \%)$ & \\
\hline 1 and 2 (non-bolus) & $17(89.5 \%)$ & $2(10.5 \%)$ & \\
\hline Dose & & & 0.079 \\
\hline 0 & $83(95.4 \%)$ & $4(4.6 \%)$ & \\
\hline 1 and 2 & $22(88 \%)$ & $3(12 \%)$ & \\
\hline
\end{tabular}

TABLE 4: Association of radiotherapy treatment and its related characteristics with local recurrence among patients diagnosed with locally advanced breast cancer.

3D-CRT: three-dimensional conformal radiotherapy; SSIMRT: step-and-shoot intensity-modulated radiotherapy; VMAT: volumetric-modulated arc therapy.

\section{Discussion}

LABC constitutes the majority of BC cases in KSA and therefore creates a major burden socially, psychologically, and economically. Understanding the factors that affect survival in patients with LABC is of paramount importance [2].

Data in the literature about the impact of a patient's age on the prognosis of BC are contradictory. Some authors reported that younger patients have a worse prognosis, whereas other authors reported elderly patients as having the worst prognosis [15-21]. Moreover, previous data in the United States, the United Kingdom, and KSA did not show any significant impact of patient age on OS and progression-free survival (PFS) in LABC $[9,22,23]$. These contradictory results could be attributed to the lack of fixed age cutoffs to define these groups (young vs elderly) among the studies.

A retrospective analysis published in 2017 was conducted on a cohort of 80 patients aged 70-96 years who were diagnosed with LABC in the Czech Republic. It showed that patients who were $\geqslant 80$ years had a worse OS, with a median of 31.6 months (19.0-44.3) (HR 2.55, 95\% CI 1.40-4.65, P = 0.002), than did patients who were $<80$ years, with a median of 78.5 months (51.4-105.5). Moreover, multivariate analysis also confirmed the significance of older age on OS in patients in the group who were $\geqslant 80$ years (HR 4.76, 95\% CI 1.22-18.61, $\mathrm{P}=0.025)[17]$.

In our study, $81.7 \%$ of patients were younger than 65 years, and women older than 65 years represented only $18.3 \%$ of the cases. Our study also showed that OS and DFS in women who are over 65 years are worse than they are in women in a younger age group. Therefore, older age could be considered a negative prognostic factor in women with LABC.

Historically, upfront mastectomy was routinely performed in patients with LABC. The introduction of neoadjuvant systemic therapies has, however, increased interest in breast-conserving surgery (BCS) in LABC 
[24]. A prospective study with patients who underwent lumpectomy following neoadjuvant chemotherapy and postoperative RT showed an OS of $78 \%$ and a local recurrence rate of $6 \%$ at 91 months, which are acceptable rates [25]. In one review in which lumpectomy was performed in $33.24 \%$ of patients and mastectomy in 66.76\%, the authors showed that the five-year DFS and OS for patients who received neoadjuvant chemotherapy and then underwent lumpectomy were $80.7 \%$ and $89.1 \%$, respectively, and that DFS and OS for those who underwent mastectomy after neoadjuvant chemotherapy were $74.6 \%$ and $84.2 \%$, respectively. There was no significant difference between the two groups $(\mathrm{P}=0.9$ and $\mathrm{P}=0.217$, respectively), which makes BCS an acceptable and safe option for patients with LABC after neoadjuvant chemotherapy [26].

A retrospective study that compared OS in patients with stage I-III BC who underwent BCS vs mastectomy showed that there was no significant difference between the two surgical approaches (HR 0.93, 95\% CI 0.751.14 , in the mastectomy group), irrespective of the adjuvant treatment received. However, the same study compared BCS and RT with mastectomy alone and revealed a significant survival benefit in the first group (HR 1.60, 95\% CI 1.36-1.89, with mastectomy alone) [27].

On the other hand, a systematic review and meta-analysis published in 2017 examined 16 studies with a total of 3,531 patients, of whom $41.5 \%$ underwent BCS and 58.5\% underwent mastectomy, to compare the outcome of surgery in patients with LABC who had a good response to neoadjuvant chemotherapy. The study showed a lower distant recurrence (odds ratio (OR) 0.51, 95\% CI 0.42-0.63, P < 0.01), a higher DFS (OR $2.35,95 \%$ CI 1.84-3.01, P < 0.01), and a higher OS (OR 2.12, 95\% CI 1.51-2.98, P < 0.01) in the BCS group than in the mastectomy group. This improvement in survival can likely be attributed to the response to neoadjuvant treatment rather than the procedure itself. Furthermore, all patients in the BCS group received RT following surgery, whereas the mastectomy group included both those who received RT following surgery and those who did not. In addition, DFS and OS were mentioned in only some of the included articles, which may have led to high heterogeneity and affected the results of the study [28]. Nonetheless, this study suggests that survival rates are not related to the surgical approach alone, but also to the response to neoadjuvant treatment and RT.

In our study, $70.6 \%$ of patients underwent mastectomy and had worse OS and DFS than did patients who underwent lumpectomy for LABC. This result can likely be attributed to the nature of the aggressive disease and not the type of surgery, as this population included patients who had a poor response or who had disease progression during neoadjuvant treatment.

Regarding the role of luminal classification in LABC and its effect on OS and DFS, we found that hormonepositive disease was associated with better OS and DFS than was hormone-negative disease. This finding was concordant with the results of multiple previous studies. A large population-based study that included 4304 women compared the OS in hormone-positive disease (ER/PR PP) with that in hormone-negative disease (ER/PR NN). The two-year OS in patients with hormone-positive disease was $93 \%$ vs $78 \%$ in hormone-negative disease $(\mathrm{P}<0.0001)[29]$.

Similar results were also observed in a prospective study that showed a significant difference in OS and PFS in favor of hormone-positive disease (ER/PR PP) ( $\mathrm{P}<0.01$ and $\mathrm{P}<0.01$, respectively), with HER2/neuenriched (ER/PR NN HER2+) and triple-negative disease (ER/PR NN HER2-) having the poorest OS and PFS [30]. This finding was further supported in other studies [31,32].

The role of targeted therapy in improving OS and DFS was not clearly demonstrated in our data, as there was a nonsignificant association. However, this might be attributed to the low prevalence of patients with HER2+ $\mathrm{BC}$ in our sample and the recent introduction of dual neoadjuvant anti-HER2 treatment at our institution. Nonetheless, other articles in the literature have shown that targeted therapy in patients with HER2+ BC improved OS in LABC [33,34].

The literature reported that patients with HER2+ disease who received neoadjuvant chemotherapy with HER2-targeted therapy and had residual disease had worse OS and DFS than did those who had a pathological complete response in early BC and LABC [33,35-38]. The current standard of care is to continue HER2-targeted therapy for one year +/- endocrine treatment for five years postoperatively [39].

Trastuzumab emtansine (T-DM1), an antibody-drug conjugate consisting of HER2-targeted therapy (trastuzumab) and a cytotoxic agent (DM1), is US Food and Drug Administration approved for patients with metastatic HER2+ disease who previously received treatment with trastuzumab and taxane, as it prolongs OS and PFS with a lower toxicity profile than does a capecitabine plus lapatinib regimen [40-44]. In 2019, a phase 3 open-label trial was conducted on post-neoadjuvant treatment with trastuzumab and taxane that included patients with non-metastatic HER2+ disease who had residual invasive disease at surgery. The patients were randomized into adjuvant T-DM1 and adjuvant trastuzumab-alone groups. Compared with trastuzumab alone, T-DM1 as adjuvant treatment was found to improve OS (HR for death 0.70, 95\% CI 0.47$1.05, \mathrm{P}=0.08$ ) and invasive DFS (HR for disease recurrence or death $0.50, \mathrm{CI} 0.39-0.64, \mathrm{P}<0.001$ ) [45].

$\mathrm{RT}$ is an integral component in the management of LABC. In operable LABC, the addition of adjuvant RT 
improves locoregional control and OS in stage III disease [46]. Even in the setting of neoadjuvant chemotherapy, postmastectomy RT was associated with a significantly reduced locoregional recurrence rate at 10 years for all patients, but more so for patients with stage III or IV disease who achieved a pathological complete response (33\% vs $3 \%$ at 10 years, $\mathrm{P}=0.006$ ) [12].

The Early Breast Cancer Trialists' Collaborative Group (EBCTCG) meta-analysis that included 8135 patients revealed that RT decreases both BC recurrence and mortality [47]. Multiple other trials, including the MA.20, the EORTC 22922-10925, and the French trial, concluded that regional RT correlated with a significant further increase in PFS (HR 0.85) and OS (HR 0.83) [48,49].

Adjuvant RT in our cohort, of whom more than half had stage T1-T2 and/or N0-1 disease, was associated with improved local control, but not with DFS or OS. A possible survival advantage in patients with more advanced stages and/or certain molecular subtypes could not be elicited because of the small sample size. A large retrospective study of 8,935 patients in Germany revealed that when RT was given in accordance with international guidelines (after mastectomy for T3-T4 or N2 disease), it was associated with improved OS [50].

Multiple authors have also found that RT improves survival for women with early triple-negative BC [51-53]. Others, however, have reported conflicting results [54,55]. In the only randomized trial to have addressed this issue, Wang et al. [52] revealed survival advantage from the addition of RT in triple-negative BC. There has therefore been growing interest in treatment escalation for women with triple-negative BC.

On the other hand, women with luminal A (ER/PR PP HER2-) or hormone-positive/HER2+ (ER/PR PP HER2+) $\mathrm{BC}$ are thought to have very low risk of locoregional recurrence. The following approaches are therefore considered reasonable for these groups and are subject to ongoing trials: (1) for luminal A BC, de-escalating treatment by omitting RT for node-negative disease after lumpectomy for older women or after mastectomy with limited nodal involvement; (2) for hormone-positive/HER2+ BC, omitting RT for complete responders to neoadjuvant chemotherapy [56-59]. Incorporating gene assays in RT decision-making is another area of growing interest $[59,60]$.

Although the local control benefit of adjuvant RT has been well documented in the literature [47,61,62], the differential effect of different technical aspects of RT has not been well studied. Our study showed that 3DCRT was associated with local control that was superior to that of IMRT/VMAT. This could simply be a reflection of more advanced disease, such as internal mammary involvement, necessitating more complex treatment, but it could also indicate a potential geographical target miss with IMRT/VMAT. A precise definition of clinical targets and a careful assessment of the needed safety margin are crucial. The variability in target delineation in most tumor sites has been associated with significant uncertainty in the RT treatment process and subsequent dose delivery, which could potentially affect local control [63,64].

The number of fields treated, which indicates breast/chest wall only vs locoregional treatment, and the use of a bolus to increase the skin dose was not associated with a difference in local control in our cohort. In accordance with the available literature, hypofractionation and standard fractionation schedules were equivalent in terms of local control [65-67].

\section{Study limitations}

Our study is one of the few to assess the outcomes and predictors of LABC in our region. Nonetheless, one of the main limitations is that it is a retrospective study, and the relatively small sample size could have affected the identification of significant predictors. As with all retrospective studies, loss of follow-up is a limiting factor; however, we maximized efforts to reach out to patients who did not come for follow-up in the last two years in order to identify those who had a recurrence, who died, or who were treated elsewhere.

\section{Conclusions}

Multiple factors can affect the OS and DFS in LABC. Younger patients, having hormone-positive disease, and undergoing a lumpectomy were associated with better outcomes. Adjuvant RT may improve local control and the use of 3D-CRT was a superior modality in terms of local control. However, prospective studies with larger sample sizes are needed to further highlight these findings and to assess the role of chemotherapy and targeted therapy in patients with LABC.

\section{Additional Information \\ Disclosures}

Human subjects: Consent was obtained or waived by all participants in this study. Unit of Biomedical Ethics Research Committee at the Faculty of Medicine, King Abdulaziz University issued approval 464-17. Approval for this study was granted by the Research Committee of the Unit of Biomedical Ethics at KAUH (Reference number 464-17). . Animal subjects: All authors have confirmed that this study did not involve animal subjects or tissue. Conflicts of interest: In compliance with the ICMJE uniform disclosure form, all authors 
declare the following: Payment/services info: All authors have declared that no financial support was received from any organization for the submitted work. Financial relationships: All authors have declared that they have no financial relationships at present or within the previous three years with any organizations that might have an interest in the submitted work. Other relationships: All authors have declared that there are no other relationships or activities that could appear to have influenced the submitted work.

\section{Acknowledgements}

We thank Dr. Ghader Jamjoum and Dr. Kholoud Awaji for their contributions to data collection.

\section{References}

1. Sung H, Ferlay J, Siegel RL, Laversanne M, Soerjomataram I, Jemal A, Bray F: Global Cancer Statistics 2020: GLOBOCAN estimates of incidence and mortality worldwide for 36 cancers in 185 countries. CA Cancer J Clin. 2021, 71:209-4. 10.3322/caac.21660

2. Saudi Cancer Registry: Cancer incidence report, Saudi Arabia, 2015 . (2018). Accessed: March 13, 2021: https://nhic.gov.sa/eServices/Documents/E\%20SCR\%20final\%206\%20NOV.pdf.

3. Allemani C, Sant M, Weir HK, et al.: Breast cancer survival in the US and Europe: a CONCORD highresolution study. Int J Cancer. 2013, 132:1170-81. 10.1002/ijc.27725

4. El Bcheraoui C, Basulaiman M, Wilson S, et al.: Breast cancer screening in Saudi Arabia: free but almost no takers. PLoS One. 2015, 10:e0119051. 10.1371/journal.pone.0119051

5. Bedwinek J, Rao DV, Perez C, Lee J, Fineberg B: Stage III and localized stage IV breast cancer: irradiation alone vs irradiation plus surgery. Int J Radiat Oncol Biol Phys. 1982, 8:31-6. 10.1016/0360-3016(82)90381-9

6. Gonzalez-Angulo AM, Hortobagyi GN: Inflammatory and locally advanced breast cancer. Management of Breast Diseases. Jatoi I, Kaufmann M (ed): Springer, Berlin, Heidelberg; 2010. 10.1007/978-3-540-69743$5 \_21$

7. Hortobagyi GN, Ames F, Buzdar A, et al.: Management of stage III primary breast cancer with primary chemotherapy, surgery, and radiation therapy. Cancer. 1988, 62:2507-16. 10.1002/10970142(19881215)62:12<2507::aid-cncr2820621210>3.0.co;2-d

8. Valagussa P, Zambetti M, Bignami P, et al.: T3b-T4 breast cancer: factors affecting results in combined modality treatments. Clin Exp Metastasis. 1983, 1:191-202. 10.1007/BF00121498

9. Kuerer HM, Newman LA, Buzdar AU, et al.: Residual metastatic axillary lymph nodes following neoadjuvant chemotherapy predict disease-free survival in patients with locally advanced breast cancer. Am J Surg. 1998, 176:502-9. 10.1016/s0002-9610(98)00253-0

10. Huang EH, Tucker SL, Strom EA, et al.: Predictors of locoregional recurrence in patients with locally advanced breast cancer treated with neoadjuvant chemotherapy, mastectomy, and radiotherapy. Int J Radiat Oncol Biol Phys. 2005, 62:351-7. 10.1016/j.ijrobp.2004.09.056

11. Meyers MO, Klauber-Demore N, Ollila DW, et al.: Impact of breast cancer molecular subtypes on locoregional recurrence in patients treated with neoadjuvant chemotherapy for locally advanced breast cancer. Ann Surg Oncol. 2011, 18:2851-7. 10.1245/s10434-011-1665-8

12. Huang EH, Tucker SL, Strom EA, et al.: Postmastectomy radiation improves local-regional control and survival for selected patients with locally advanced breast cancer treated with neoadjuvant chemotherapy and mastectomy. J Clin Oncol. 2004, 22:4691-9. 10.1200/JCO.2004.11.129

13. But-Hadzić J, Bilban-Jakopin C, Hadzić V: The role of radiation therapy in locally advanced breast cancer . Breast J. 2010, 16:183-8. 10.1111/j.1524-4741.2009.00885.x

14. Edge SB, Compton CC: The American Joint Committee on Cancer: the 7th edition of the AJCC cancer staging manual and the future of TNM. Ann Surg Oncol. 2010, 17:1471-4. 10.1245/s10434-010-0985-4

15. De La Rochefordiere A, Campana F, Fenton J, et al.: Age as prognostic factor in premenopausal breast carcinoma. Lancet. 1993, 341:1039-43. 10.1016/0140-6736(93)92407-k

16. Gnerlich JL, Deshpande AD, Jeffe DB, Sweet A, White N, Margenthaler JA: Elevated breast cancer mortality in women younger than age 40 years compared with older women is attributed to poorer survival in earlystage disease. J Am Coll Surg. 2009, 208:341-7. 10.1016/j.jamcollsurg.2008.12.001

17. Hornova J, Bortlicek Z, Majkova P, et al.: Locally advanced breast cancer in elderly patients . Biomed Pap Med Fac Univ Palacky Olomouc Czech Repub. 2017, 161:217-22. 10.5507/bp.2017.011

18. Nixon AJ, Neuberg D, Hayes DF, et al.: Relationship of patient age to pathologic features of the tumor and prognosis for patients with stage I or II breast cancer. J Clin Oncol. 1994, 12:888-94. 10.1200/JCO.1994.12.5.888

19. Sweeting RS, Klauber-Demore N, Meyers MO, et al.: Young women with locally advanced breast cancer who achieve breast conservation after neoadjuvant chemotherapy have a low local recurrence rate. Am Surg. 2011, 77:850-5. 10.1177/000313481107700718

20. Xiong Q, Valero V, Kau V, et al.: Female patients with breast carcinoma age 30 years and younger have a poor prognosis: the M.D. Anderson Cancer Center experience. Cancer. 2001, 92:2523-8. 10.1002/10970142(20011115)92:10<2523::aid-cncr1603>3.0.c0;2-6

21. Villarreal-Garza C, Lopez-Martinez EA, Muñoz-Lozano JF, Unger-Saldaña K: Locally advanced breast cancer in young women in Latin America. Ecancermedicalscience. 2019, 13:894. 10.3332/ecancer.2019.894

22. Ezzat AA, Ibrahim EM, Raja MA, Al-Sobhi S, Rostom A, Stuart RK: Locally advanced breast cancer in Saudi Arabia: high frequency of stage III in a young population. Med Oncol. 1999, 16:95-103. 10.1007/BF02785842

23. Honkoop AH, van Diest PJ, de Jong JS, et al.: Prognostic role of clinical, pathological and biological characteristics in patients with locally advanced breast cancer. Br J Cancer. 1998, 77:621-6. 10.1038/bjc.1998.99

24. Touboul E, Buffat L, Lefranc J-P, et al.: Possibility of conservative local treatment after combined chemotherapy and preoperative irradiation for locally advanced noninflammatory breast cancer. Int J Radiat 
Oncol Biol Phys. 1996, 34:1019-28. 10.1016/0360-3016(95)02207-4

25. Shen J, Valero V, Buchholz TA, et al.: Effective local control and long-term survival in patients with T4 locally advanced breast cancer treated with breast conservation therapy. Ann Surg Oncol. 2004, 11:854-60. 10.1245/ASO.2004.02.003

26. Cho JH, Park JM, Park HS, Park S, Kim SI, Park BW: Oncologic safety of breast-conserving surgery compared to mastectomy in patients receiving neoadjuvant chemotherapy for locally advanced breast cancer. J Surg Oncol. 2013, 108:531-6. 10.1002/jso.23439

27. Onitilo AA, Engel JM, Stankowski RV, Doi SA: Survival comparisons for breast conserving surgery and mastectomy revisited: community experience and the role of radiation therapy. Clin Med Res. 2015, 13:6573. 10.3121/cmr.2014.1245

28. Sun Y, Liao M, He L, Zhu C: Comparison of breast-conserving surgery with mastectomy in locally advanced breast cancer after good response to neoadjuvant chemotherapy: a PRISMA-compliant systematic review and meta-analysis. Medicine. 2017, 96:e8367. 10.1097/MD.0000000000008367

29. Dawood S, Ueno NT, Valero V, et al.: Differences in survival among women with stage III inflammatory and noninflammatory locally advanced breast cancer appear early: a large population-based study. Cancer. 2011, 117:1819-26. 10.1002/cncr.25682

30. Sørlie T, Perou CM, Tibshirani R, et al.: Gene expression patterns of breast carcinomas distinguish tumor subclasses with clinical implications. Proc Natl Acad Sci U S A. 2001, 98:10869-74. 10.1073/pnas.191367098

31. Bonnefoi H, Diebold-Berger S, Therasse P, et al.: Locally advanced/inflammatory breast cancers treated with intensive epirubicin-based neoadjuvant chemotherapy: are there molecular markers in the primary tumour that predict for 5-year clinical outcome?. Ann Oncol. 2003, 14:406-13. 10.1093/annonc/mdg108

32. Stewart JF, King RJ, Winter PJ, Tong D, Hayward JL, Rubens RD: Oestrogen receptors, clinical features and prognosis in stage III breast cancer. Eur J Cancer Clin Oncol. 1982, 18:1315-20. 10.1016/02775379(82)90135-3

33. Gianni L, Eiermann W, Semiglazov V, et al.: Neoadjuvant and adjuvant trastuzumab in patients with HER2positive locally advanced breast cancer (NOAH): follow-up of a randomised controlled superiority trial with a parallel HER2-negative cohort. Lancet Oncol. 2014, 15:640-7. 10.1016/S1470-2045(14)70080-4

34. Kannanavil N, Padinjarenalakath NT, Vilayapoyilil A, Karatparambil A: Immunohistochemistry profile and its relation with prognosis in locally advanced breast cancer. Int Surg J. 2019, 6:4507-11. 10.18203/23492902.isj20195421

35. Cortazar P, Zhang L, Untch M, et al.: Pathological complete response and long-term clinical benefit in breast cancer: the CTNeoBC pooled analysis. Lancet. 2014, 384:164-72. 10.1016/S0140-6736(13)62422-8

36. de Azambuja E, Holmes AP, Piccart-Gebhart M, et al.: Lapatinib with trastuzumab for HER2-positive early breast cancer (NeoALTTO): survival outcomes of a randomised, open-label, multicentre, phase 3 trial and their association with pathological complete response. Lancet Oncol. 2014, 15:1137-46. 10.1016/S14702045(14)70320-1

37. Schneeweiss A, Chia S, Hickish T, et al.: Long-term efficacy analysis of the randomised, phase II TRYPHAENA cardiac safety study: Evaluating pertuzumab and trastuzumab plus standard neoadjuvant anthracycline-containing and anthracycline-free chemotherapy regimens in patients with HER2-positive early breast cancer. Eur J Cancer. 2018, 89:27-35. 10.1016/j.ejca.2017.10.021

38. Untch M, Fasching PA, Konecny GE, et al.: Pathologic complete response after neoadjuvant chemotherapy plus trastuzumab predicts favorable survival in human epidermal growth factor receptor 2-overexpressing breast cancer: results from the TECHNO trial of the AGO and GBG study groups. J Clin Oncol. 2011, 29:33517. 10.1200/JCO.2010.31.4930

39. National Comprehensive Cancer Network: NCCN clinical practice guidelines in oncology: breast cancer version 3.2021. (2021). Accessed: April 5,2021: https://www.nccn.org/professionals/physician_gls/pdf/breast.pdf.

40. Genentech, Inc. KADCYLA ${ }^{\circledR}$ (ado-trastuzumab emtansine) for injection, for intravenous use . (2019). https://www.accessdata.fda.gov/drugsatfda_docs/label/2019/125427s105lbl.pdf.

41. Diéras V, Miles D, Verma S, et al.: Trastuzumab emtansine versus capecitabine plus lapatinib in patients with previously treated HER2-positive advanced breast cancer (EMILIA): a descriptive analysis of final overall survival results from a randomised, open-label, phase 3 trial. Lancet Oncol. 2017, 18:732-4. 10.1016/S1470-2045(17)30312-1

42. Krop IE, Kim SB, González-Martín A, et al.: Trastuzumab emtansine versus treatment of physician's choice for pretreated HER2-positive advanced breast cancer (TH3RESA): a randomised, open-label, phase 3 trial. Lancet Oncol. 2014, 15:689-99. 10.1016/S1470-2045(14)70178-0

43. Krop IE, Kim SB, Martin AG, et al.: Trastuzumab emtansine versus treatment of physician's choice in patients with previously treated HER2-positive metastatic breast cancer (TH3RESA): final overall survival results from a randomised open-label phase 3 trial. Lancet Oncol. 2017, 18:743-54. 10.1016/S14702045(17)30313-3

44. Verma S, Miles D, Gianni L, et al.: Trastuzumab emtansine for HER2-positive advanced breast cancer. N Engl J Med. 2012, 367:1783-91. 10.1056/NEJMoa1209124

45. von Minckwitz G, Huang CS, Mano MS, et al.: Trastuzumab emtansine for residual invasive HER2-positive breast cancer. N Engl J Med. 2019, 380:617-28. 10.1056/NEJMoa1814017

46. Olson JE, Neuberg D, Pandya KJ, et al.: The role of radiotherapy in the management of operable locally advanced breast carcinoma: results of a randomized trial by the Eastern Cooperative Oncology Group. Cancer. 1997, 79:1138-49. 10.1002/(SICI)1097-0142(19970315)79:6<1138::AID-CNCR12>3.0.CO;2-0

47. McGale P, Taylor C, Correa C, et al.: Effect of radiotherapy after mastectomy and axillary surgery on 10-year recurrence and 20-year breast cancer mortality: meta-analysis of individual patient data for 8135 women in 22 randomised trials. Lancet. 2014, 383:2127-35. 10.1016/S0140-6736(14)60488-8

48. Bartelink H, Horiot JC, Poortmans P, et al.: Recurrence rates after treatment of breast cancer with standard radiotherapy with or without additional radiation. N Engl J Med. 2001, 345:1378-87. 10.1056/NEJMoa010874

49. Mulliez T, Veldeman L, De Neve W: Regional nodal irradiation in early-stage breast cancer . N Engl J Med. 2015, 373:1878. 10.1056/NEJMc1510505 
50. Wöckel A, Wolters R, Wiegel T, et al.: The impact of adjuvant radiotherapy on the survival of primary breast cancer patients: a retrospective multicenter cohort study of 8935 subjects. Ann Oncol. 2014, 25:628-32. 10.1093/annonc/mdt584

51. Schwentner L, Wolters R, Koretz K, Wischnewsky MB, Kreienberg R, Rottscholl R, Wöckel A: Triple-negative breast cancer: the impact of guideline-adherent adjuvant treatment on survival--a retrospective multicentre cohort study. Breast Cancer Res Treat. 2012, 132:1073-80. 10.1007/s10549-011-1935-y

52. Wang J, Shi M, Ling R, et al.: Adjuvant chemotherapy and radiotherapy in triple-negative breast carcinoma: a prospective randomized controlled multi-center trial. Radiother Oncol. 2011, 100:200-4. 10.1016/j.radonc.2011.07.007

53. Yao Y, Chu Y, Xu B, Hu Q, Song Q: Radiotherapy after surgery has significant survival benefits for patients with triple-negative breast cancer. Cancer Med. 2019, 8:554-63. 10.1002/cam4.1954

54. Dragun AE, Pan J, Rai SN, Kruse B, Jain D: Locoregional recurrence in patients with triple-negative breast cancer: preliminary results of a single institution study. Am J Clin Oncol. 2011, 34:231-7. 10.1097/COC.0b013e3181dea993

55. Moran MS, Zhao Y, Ma S, et al.: Association of radiotherapy boost for ductal carcinoma in situ with local control after whole-breast radiotherapy. JAMA Oncol. 2017, 3:1060-8. 10.1001/jamaoncol.2016.6948

56. Garg AK, Buchholz TA: Influence of neoadjuvant chemotherapy on radiotherapy for breast cancer . Ann Surg Oncol. 2015, 22:1434-40. 10.1245/s10434-015-4402-x

57. Horton JK, Jagsi R, Woodward WA, Ho A: Breast cancer biology: clinical implications for breast radiation therapy. Int J Radiat Oncol Biol Phys. 2018, 100:23-37. 10.1016/j.ijrobp.2017.08.025

58. Kunkler I, Canney P, Van Tienhoven G, et al.: P88 MRC/EORTC (BIG 2-04) SUPREMO-a phase III trial assessing the role of chest wall irradiation in 'intermediate-risk' breast cancer. Breast. 2007, 16:37. 10.1016/S0960-9776(07)70153-4

59. Whelan T: Clinical benefit according to biologic subtype and extent of disease: who should not receive radiation?. Breast. 2019, 44:9. 10.1016/S0960-9776(19)30089-X

60. Damico N, Kharouta M, Lyons JA, Harris EE: Radiation therapy following breast conserving surgery (BCS) in women with early-stage breast cancer and low oncotype scores. J Clin Oncol. 2020, 38:e12547. 10.1200/JCO.2020.38.15_suppl.e12547

61. Krug D: Adjuvant radiotherapy for breast cancer: more than meets the eye . Breast Care. 2020, 15:109-11. 10.1159/000506797

62. Darby S, McGale P, Correa C, et al.: Effect of radiotherapy after breast-conserving surgery on 10-year recurrence and 15-year breast cancer death: meta-analysis of individual patient data for 10,801 women in 17 randomised trials. Lancet. 2011, 378:1707-16. 10.1016/S0140-6736(11)61629-2

63. Gee HE, Moses L, Stuart K, et al.: Contouring consensus guidelines in breast cancer radiotherapy: Comparison and systematic review of patterns of failure. J Med Imaging Radiat Oncol. 2019, 63:102-15. 10.1111/1754-9485.12804

64. Segedin B, Petric P: Uncertainties in target volume delineation in radiotherapy - are they relevant and what can we do about them?. Radiol Oncol. 2016, 50:254-62. 10.1515/raon-2016-0023

65. Haviland JS, Owen JR, Dewar JA, et al.: The UK Standardisation of Breast Radiotherapy (START) trials of radiotherapy hypofractionation for treatment of early breast cancer: 10-year follow-up results of two randomised controlled trials. Lancet Oncol. 2013, 14:1086-94. 10.1016/S1470-2045(13)70386-3

66. Koulis TA, Nichol AM, Truong PT, et al.: Hypofractionated adjuvant radiation therapy is effective for patients with lymph node-positive breast cancer: a population-based analysis. Int J Radiat Oncol Biol Phys. 2020, 108:1150-8. 10.1016/j.ijrobp.2020.07.2313

67. Whelan TJ, Pignol JP, Levine MN, et al.: Long-term results of hypofractionated radiation therapy for breast cancer. N Engl J Med. 2010, 362:513-20. 10.1056/NEJMoa0906260 